\title{
Studies of the effect of D-penicillamine and sodium aurothiomalate therapy on superoxide anion production by monocytes from patients with rheumatoid arthritis: evidence for in vivo stimulation of monocytes
}

\author{
N P HURST, * A L BELL, $\dagger$ AND G NUKI \\ From the Rheumatic Diseases Unit, Department of Medicine (WGH), University of Edinburgh, Northern \\ General Hospital, Ferry Road, Edinburgh
}

SUMMARY The capacity of monocytes from patients with rheumatoid arthritis to generate superoxide anion in vitro after stimulation with serum treated zymosan (STZ) or IgG treated zymosan (IgTZ) was studied before and during therapy with penicillamine $(n=9)$ or sodium aurothiomalate (AuTM) $(n=12)$. Significant increases in rates of STZ $(p<0 \cdot 01)$ and IgTZ $(\mathrm{p}<0.02)$ stimulated superoxide anion production were seen after successful therapy (14 patients), which were paralleled by a significant increase in serum thiol levels. Patients who did not respond clinically to therapy $(n=4)$ showed a smaller mean increase in serum thiol levels and had high mean rates of in vitro superoxide production before and after second-line therapy. Three patients were withdrawn from the study. The data suggest that successful therapy with penicillamine or AuTM may be associated with monocyte activation, and possible mechanisms are discussed.

Key word: phagocytes.

Previous workers have found biochemical evidence for free radical mediated oxidative damage in patients with rheumatoid arthritis (RA), including reduced availability of serum thiol groups, reduced levels of erythrocyte superoxide dismutase,${ }^{1}$ and the presence of free radical oxidation products of lipids. $^{2}$ It has been suggested that low serum thiol levels in early RA indicate a poor prognosis. ${ }^{3}$ In vitro studies have also emphasised the ability of oxygen free radicals to damage connective tissue constituents such as hyaluronic acid ${ }^{4}$ and collagen. ${ }^{5}$

During inflammatory reactions both polymorphonuclear leucocytes and mononuclear phagocytes are an important source of oxygen free radicals. Pha-

\section{Accepted for publication 24 June 1985.}

Correspondence to Dr N P Hurst, Rheumatology Unit, Queen Elizabeth Hospital, Woodville, South Australia 5011.

Present addresses: *Rheumatology Unit, Queen Elizabeth Hospital, Woodville, South Australia 5011; †Department of Rheumatology, Musgrave Park Hospital, Stockmans Lane, Belfast, BT9 7JB. gocytic cells will respond with a burst of oxygen consumption and oxygen free radical release to a number of soluble and particulate stimuli, including C5a and immune complexes, ${ }^{6}$ opsonised organisms, ${ }^{9}$ and non-immune stimuli such as phorbol myristate acetate ${ }^{8}$ formyl-methionyl tripeptides, ${ }^{9}$ and fluoride ion. ${ }^{10}$ Since rheumatoid synovium contains numerous marrow derived mononuclear phagocytes, ${ }^{11}$ the capacity of these cells to generate oxygen free radicals and the influence of antirheumatic therapy on this function is of some interest.

It has been suggested that the mechanism of action of drugs such as sodium aurothiomalate (AuTM) and penicillamine may include both a free radical scavenging effect ${ }^{12}$ and possibly an inhibitory effect on oxygen free radical release by phagocytes. ${ }^{13}$ Similar observations have been made concerning non-steroidal anti-inflammatory drugs (NSAIDs). ${ }^{14}$ However, in a previous study of monocyte superoxide anion production ${ }^{16}$ we found 
that monocytes from RA patients on second-line therapy with penicillamine or AuTM showed enhanced superoxide generating capacity in response to immune stimuli compared with normal controls or RA patients on NSAIDs alone, and the increase could not be attributed to increased disease activity. To substantiate this observation we have undertaken a prospective study of superoxide generation by monocytes from patients before and after commencing treatment with AuTM or penicillamine.

\section{Patients and methods}

\section{SUPEROXIDE ANION PRODUCTION}

Freshly drawn human venous blood was anticoagulated with $10 \mathrm{mM}$ ethylenediaminetetra-acetic acid and the mononuclear cells (monocytes and lymphocytes) were separated according to the method of Boyum $^{17}$ on a density gradient (Lymphoprep, Nyegaard, Oslo). Indicator free Hanks's balanced salt solution (HBSS) with 5 units $/ \mathrm{ml}$ of preservative free heparin was used throughout for washing and incubation of cells. The mononuclear cell fraction was washed twice and resuspended to give a final monocyte concentration of between 0.6 and $1.2 \times$ $10^{6} / \mathrm{ml}\left(1.2 \times 10^{9} / 1\right)$. Exact concentrations of monocytes and lymphocytes in the final suspension were determined with a ZBI Coulter counter as previously described ${ }^{18}$ and with non-specific esterase stains of cytosmears of mononuclear cells. ${ }^{19}$

Zymosan opsonised either with serum or human IgG was used to stimulate superoxide anion release. Zymosan was opsonised in bulk with fresh human serum (STZ) from a single donor in a ratio of $10 \mathrm{mg}$ zymosan $/ \mathrm{ml}$ serum, or with pooled human IgG (IgTZ) (SE Scotland Blood Transfusion Service) in a ratio of $10 \mathrm{mg}$ zymosan $/ 75 \mathrm{mg} \mathrm{IgG/ml} \mathrm{HBSS}$. Opsonisation was carried out at $37^{\circ} \mathrm{C}$ for 30 minutes, the zymosan washed three times in HBSS and resuspended to give a ratio of $50 \mathrm{mg}$ zymosan $/ \mathrm{ml}$ HBSS. After opsonisation the zymosan was stored in $0.25 \mathrm{ml}$ aliquots in liquid nitrogen until ready for use.

Superoxide anion was measured by the reduction of horse heart ferricytochrome c (type III, Sigma) as previously described. ${ }^{20}$ All experiments were performed in duplicate plastic tubes $(9 \times 11 \mathrm{~mm}$, RT 25 , Sterilin). $450 \mu \mathrm{l}$ aliquots of mononuclear cell suspension were mixed with $50 \mu$ l of cytochrome $c$ in HBSS $(200 \mu \mathrm{M}$ final) and $25 \mu \mathrm{l}$ of a suspension of STZ or IgTZ. Tubes were capped and incubated on a turntable for timed intervals as indicated below. The reaction was terminated by placing the tubes in iced water for 10 minutes and then centrifuging at $1000 \mathrm{~g}$ for 10 minutes. The extent of cytochrome $\mathrm{c}$ reduction in the supernatant was measured as then change in absorbance at $550 \mathrm{~nm}$ after the addition of: a grain of potassium ferricyanide, in a Cecil spectro? photometer using an extinction coefficient of $21 \cdot 1 \mathrm{mM}^{-1} \mathrm{~cm}^{-1}$. ${ }^{21}$ The total amount of cytochrome c was obtained from the absorption at $550 \mathrm{~nm}$ aftee the addition of a few grains of sodium dithionite? Control studies confirmed that for a given stimulus the reduction of cytochrome $c$ followed first-order kinetics over 60 minutes and that the rate wasdirectly proportional to the monocyte concentration $\vec{\omega}$ A rate constant $\mathrm{K}$ for reduction of cytochrome $\mathrm{c} b \mathrm{~b}$ superoxide could thus be obtained from:

$$
K=\frac{1}{t+M o} \times \ln \frac{\text { cyt } c^{\circ}}{\text { cyt } c^{1}} \mathrm{mV} / \mathrm{min} / \text { monocyte }
$$

where $\mathrm{t}=$ time (minutes); Mo=monocyte concentra $=$ tion; cyt $c^{\circ}$ and cyt $c^{t}$ are the concentrations of oxidised cytochrome $\mathrm{c}$ initially and after $\mathrm{t}$ minutes incubation respectively. Rates of reduction of cytochrome $c$ are expressed in terms of this rate constant. In each subject the rate constants for STZO and IgTZ stimulated superoxide production wereo obtained by measuring the mean rate of cytochrome c reduction over a time course $(0,5,15$ minutes) in the presence of $2.5 \mathrm{mg} / \mathrm{ml}(\mathrm{g} / \mathrm{l})$ of STZ or IgTZ.

PATIENTS AND CONTROLS

Eighteen healthy hospital and laboratory employees (five male, 13 female) mean age 33.5 years (range 23-64), and 21 patients with classical or definite $\mathrm{RA}^{22}$ (seven male, 14 female) mean age 51.4 years (range 34-73) were studied. The inclusion criteriä for patients entering the study were active disease requiring second-line therapy as judged by early morning stiffness (EMS) $>1 \mathrm{~h}$, erythrocyte sedi mentation rate (ESR) $>30 \mathrm{~mm} / 1 \mathrm{st} h$ (Westergren) and the presence of active synovitis in more than four joints or groups of joints. All patients had received only non-steroidal anti-inflammatory drugs (NSAIDs) in the three months before entry into the study. Twelve patients received AuTM $50 \mathrm{mg} /$ week intramuscularly; nine received penicillamine in dose of $125 \mathrm{mg} / \mathrm{day}$, increasing by $125 \mathrm{mg}$ incre $\tilde{D}$ ments at monthly intervals.

Measurement of the rate constant (K) for in vitr monocyte superoxide anion production, ESR haemoglobin, white cell count, rheumatoid factorळ and serum total free thiols by Ellman's method $\stackrel{209}{?}$ were undertaken before commencing therapy, ato three to four months after starting therapy, and iP the case of patients showing no or indefinite response to therapy again after six months of therapy. A clinical assessment of the patient was made at each of the time intervals which includeg 
Table 1 Clinical score*

\begin{tabular}{|c|c|c|c|}
\hline Score & +1 & 0 & -1 \\
\hline ESR & $\begin{array}{l}\text { Fall in ESR }>25 \mathrm{~mm} / 1 \mathrm{st} \mathrm{h} \\
\text { or normal ESR }\end{array}$ & Fall in ESR $<25 \mathrm{~mm} / 1 \mathrm{st} \mathrm{h}$ & Rise in ESR $>10 \mathrm{~mm} / 1 \mathrm{st} \mathrm{h}$ \\
\hline EMS & $\begin{array}{l}\text { Fall in EMS }>2 \mathrm{~h} \\
\quad \text { or EMS }<1 \mathrm{~h}\end{array}$ & No change & $\begin{array}{l}\text { Rise in EMS or } \\
\text { EMS }>4 \mathrm{~h}\end{array}$ \\
\hline Global & Better & No change & Worse \\
\hline
\end{tabular}

*Maximum score $=+3$; minimum score $=-3$.

duration of EMS and a global assessment of the patients response to therapy (better, worse, or no change).

The success or failure of therapy was judged by a composite clinical score based on change in EMS, ESR, and a global assessment of response to therapy (Table 1). A total score of +1 or more was judged a response and 0 or less a failure. Each individual study was terminated when the patient was judged to have responded or had received six months' therapy without improvement. Three patients were withdrawn from the study; one patient on penicillamine did not wish to continue participating after 10 weeks, two patients on AuTM developed rashes necessitating withdrawal of therapy. The experimental data on these three patients are presented separately.

Students' $t$ test, either paired or unpaired, was used for statistical comparisons wherever appropriate.

\section{Results}

CLINICAL STUDIES

There was no significant difference in disease activity between the responders and non-responders before therapy as judged by duration of early morning stiffness (EMS) or erythrocyte sedimentation rate (ESR) (Table 2). All patients were strongly seropositive for rheumatoid factor (RF), except for one non-responder who was seronegative. All patients continued with the same NSAID therapy during the period of study.

Table 2 Disease activity before therapy in responders $(R)$ and non-responders (NR)

\begin{tabular}{lrl}
\hline & $R(n=14)$ & $N R(n=4)$ \\
\hline ESR (mm/1st hour) & $74 \cdot 4 \pm 5 \cdot 9^{*}$ & $72 \cdot 0 \pm 17 \cdot 3$ \\
EMS (hours) & $3 \cdot 3 \pm 0 \cdot 29$ & $3 \cdot 25 \pm 0 \cdot 75$ \\
\hline
\end{tabular}

*Values are mean \pm SEM.
RESPONSE TO THERAPY

Responders to second-line therapy showed significant falls in ESR and log titre of rheumatoid factor and improvement in clinical score; the number of non-responders is too small for statistical analysis, but these subjects showed no fall in ESR or log titre of rheumatoid factor and a deterioration in clinical score (Fig. 1).

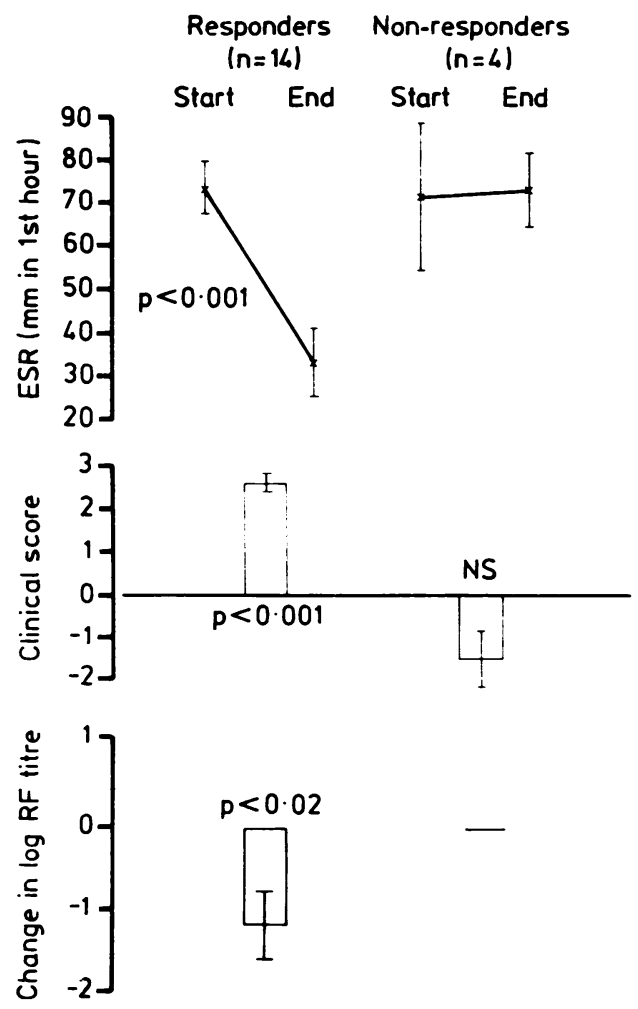

Fig. 1 Changes in ESR, rheumatoid factor $(R F)$ titre, and clinical score in responders $(R)$ and non-responders $(N R)$ to second-line therapy. Responders showed significant falls in ESR and log titre of RF and improvement in clinical score, whereas non-responders did not. 


\section{SUPEROXIDE ANION PRODUCTION}

There was no significant difference in rates of stimulated monocyte superoxide anion production between normal controls or responders to secondline therapy before starting treatment. However, after therapy a significant rise was seen in rates of superoxide release by monocytes from 'responders' when stimulated with either STZ $(p<0.01)$ or IgTZ $(p<0.02)$. The number of non-responders is too small for statistical analysis, but it can be seen that the mean rate of superoxide release by monocytes from the four non-responders was high both before and after therapy (Fig. 2).

Levels of serum thiols in responders were significantly lower than those of controls before therapy $(p<0.01)$ and rose significantly $(p<0.01)$ after therapy to normal levels. The changes are thus concordant with superoxide production by monocytes from

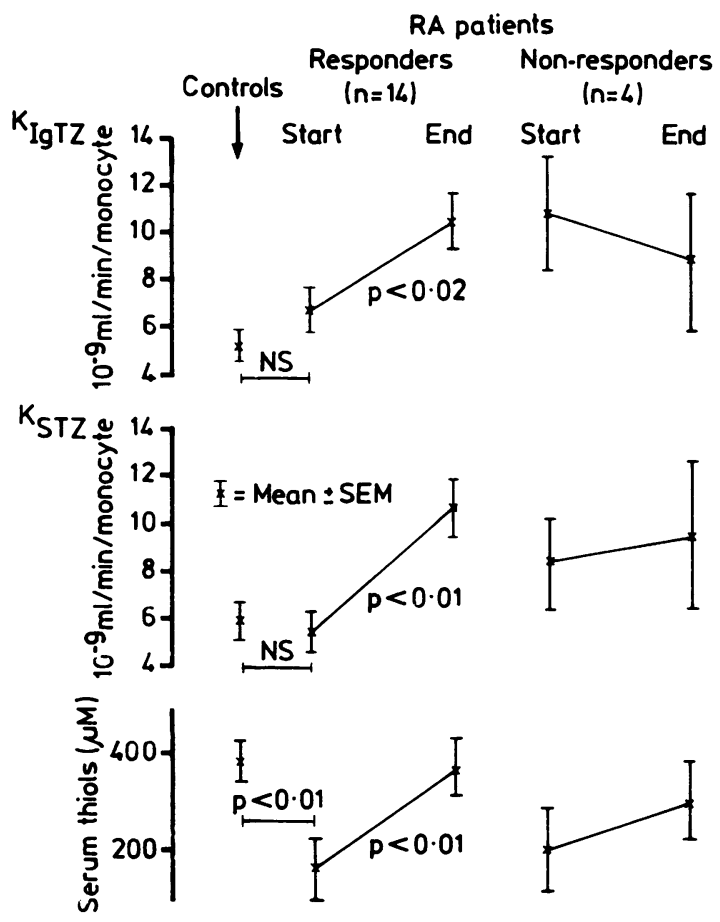

Fig. 2 Change in rates of stimulated monocyte superoxide production in vitro and serum thiol levels in controls and $R A$ patients. After second-line therapy monocytes from responders $(R)$ show a significant rise in rates of superoxide production in vitro which is paralleled by a significant rise in serum thiols. Monocyte superoxide production by monocytes from non-responders was high before and after therapy, and a small rise was seen in serum thiol levels. responders. In two of the four non-responders levels of serum thiols were essentially unchanged afte $\vec{F}$ therapy, while in the other two a rise in thiols was? seen. The mean increase in serum thiols in nonresponders $(50 \mu \mathrm{M})$ was half that of the responders $(100 \mu \mathrm{M})$ (Fig. 2).

WITHDRA WALS FROM STUDY

Three patients withdrew from the study.

Patient A declined to participate in the study after10 weeks of therapy but none the less wished tow continue penicillamine. By the 10th week a sharpo rise in serum thiols and rates of stimulated superox? ide release had occurred, but it was not clear at that stage whether the patient was responding clinically to penicillamine therapy. At follow up four months

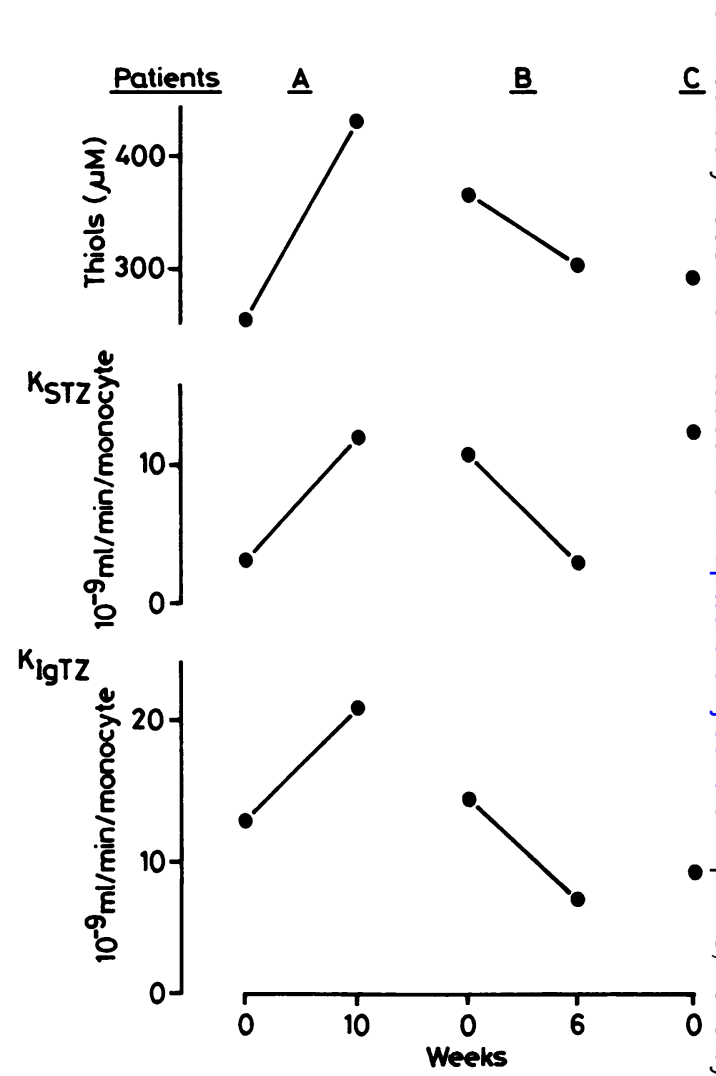

Fig. 3 Serum thiol levels and rates of monocyte superoxid production in three patients withdrawn from the study. Patient $A$ showed a rise in thiols and rates of superoxide production at 10 weeks of therapy comparable to the responder group of patients. This patient subsequently underwent complete remission. Patient $B$ had already started on chloroquine at the time of the second set of measurements. Only pretreatment values are available for patient $C$. 
after commencing penicillamine he was found to be in clinical remission with no EMS and normal ESR. The initial rise in serum thiols and rate of superoxide release follow those of the responder group (Fig. 3).

Patient B developed a skin rash after $230 \mathrm{mg}$ of AuTM and was started on hydroxychloroquine 400 $\mathrm{mg} /$ day by her attending physician; the latter drug was introduced four days before the second measurement of superoxide anion generation. Serum thiol levels and rates of superoxide release fell in this patient (Fig. 3).

Patient $\mathrm{C}$ developed a skin rash on treatment with AuTM. Only pretreatment values of serum thiols and superoxide production are available (Fig. 3).

\section{Discussion}

We have previously found ${ }^{16}$ that monocytes from RA patients on second-line therapy unexpectedly showed enhanced superoxide release in response to opsonised zymosan compared with normal controls or patients on NSAIDs alone. Although the effect did not appear to be due to increased disease activity, this possibility could not be satisfactorily excluded. No increase was seen in response to fluoride ion, a biochemical stimulus which does not involve membrane receptors, and it therefore seemed likely that surface receptors which bind opsonised zymosan were involved in mediating the increased superoxide release. No differences were found either in basal unstimulated levels of superoxide production or in levels of 'non-dismutase inhibitable' reducing activity (i.e. cytochrome $\mathrm{c}$ reduction not attributable to superoxide anion). Furthermore AuTM and penicillamine had no enhancing effect on monocyte superoxide production in vitro (unpublished observations), suggesting that the mechanism of the in vivo effect is indirect.

The results we now report confirm that the capacity of blood monocytes to generate superoxide anion in response to zymosan opsonised with serum or IgG increases during successful therapy with AuTM or penicillamine and is not related to increased disease activity. Furthermore, this increase is accompanied by a rise in serum free thiol levels. An identical pattern was seen after one month in one of the patients who withdrew from the experimental part of the study, but continued with and later responded to penicillamine treatment. Although the number of 'non-responders' is small, the data suggest that monocytes from these individuals behave differently. The mean rate of superoxide generation by monocytes from nonresponders was high both before and after therapy and suggests a possible biological difference between the responder and non-responder group of patients. In the responder group the association of enhanced monocyte free radical release in vitro with reduction in disease activity and rise in serum free thiols raises some important questions concerning the mode of action of penicillamine and AuTM and the role of mononuclear phagocyte derived oxygen free radicals in $\mathrm{RA}$.

The mechanisms by which penicillamine and AuTM might be acting (directly or indirectly) include enhancement of monocyte membrane receptor expression, enhancement of the biochemical mechanisms linking receptors to the membrane superoxide generating system, or a combination of both. Previous workers have shown increased monocyte $\mathrm{Fc}$ receptor (FcR) expression and increased antibody-dependent cell cytotoxicity in a variety of chronic inflammatory diseases including RA, ${ }^{2-26}$ and this may reflect enhancement of subclasses of FcR which mediate respiratory burst activity. ${ }^{27} 28$ Increased FcR expression and oxygen free radical release are manifestations of phagocyte activation and occur in response to a variety of chronic inflammatory stimuli. ${ }^{29}$ Thus one interpretation of our data is that second-line agents act by enhancing mechanisms of phagocyte activation in patients in whom these mechanisms have been impaired. Paradoxically, impairment of the superoxide generating system might occur during chronic inflammation as a consequence of free radical release by phagocytes. For example, receptordependent superoxide release in phagocytes requires $S$-adenosyl methionine dependent methylation reactions, ${ }^{30}$ but this process may be inhibited during the respiratory burst by oxidation of substrate methionine to methionine sulphoxide. ${ }^{31} 32$ The precise role of such methylation reactions has yet to be fully defined but includes: $(a)$ methylation of phosphatidyl ethanolamine to phosphatidyl choline, a reaction which is believed to be important in maintaining membrane fluidity and supporting transmembrane signalling, ${ }^{33}$ and $(b)$ carboxy- $O$ methylation of membrane glycoproteins, a reaction which has a role in determining the functional state of such proteins. ${ }^{34}$ Further evidence to support the concept that monocytes may be damaged by oxygen free radicals has been provided by McKeown et al. ${ }^{35}$ They have shown that monocytes from RA patients display poor accessory cell function compared with normal controls or RA patients receiving Dpenicillamine. Furthermore the abnormality could be corrected in vitro by treating defective monocytes with the simple thiol compound 2-mercaptoethanol and, conversely, reproduced by treating normal monocytes with the sulphydryl blocking agent, p-hydroxymercuriphenylsulphonic acid.

Whatever the interpretation, our observations 
raise important questions concerning the biological role of monocyte derived free radicals and contradict the widely held assumption that oxygen free radicals, regardless of their source, are necessarily deleterious. For example, the ability of mononuclear phagocytes to generate oxygen free radicals is clearly of importance in the killing of a number of obligate intracellular bacteria and parasites, ${ }^{736}$ and enhancement of this function is a feature of monocyte activation in vivo ${ }^{36}$ and in vitro. ${ }^{37}$ The involvement of oxygen free radicals during interaction of macrophages with $T$ and $B$ cells is controversial. Some studies suggest that $\mathrm{T}$ cell anergy may be a consequence of excessive macrophage hydrogen peroxide and prostaglandin $\mathrm{E}$ production. ${ }^{38} \mathrm{How}-$ ever, there is also evidence that $T$ lymphocyte mitogenesis can be inhibited by free radical scavengers and furthermore that inhibition is more marked with macrophage-dependent mitogens. ${ }^{39}$ Other experiments have demonstrated that oxidising agents not only stimulate $T$ lymphocyte proliferation but also generate suppressor cell activity, thereby inhibiting $B$ cell immunoglobulin synthesis. ${ }^{40}$ Thus failure of macrophage activation and poor oxygen free radical responses might have a role in the abnormal immunoregulation associated with autoimmune processes. The initiating cause of RA is unknown, but the pattern and spectrum of immune responses bear a strong resemblance to those of chronic infectious disease such as leprosy, ${ }^{41}$ in which there is a correlation between macrophage activation and the immune status of the host. Thus changes in activation of mononuclear phagocytes and their capacity for oxygen free radical generation may also reflect alterations in the immunological spectrum of RA which accompany therapy with drugs such as penicillamine. ${ }^{42}$

In conclusion our data confirm that penicillamine and gold therapy in RA enhances receptor mediated superoxide generation by monocytes, though the mechanism is not clear. These observations raise important questions about the inflammatory and immunoregulatory role of superoxide anion during the rheumatoid process. Studies are now in progress to determine whether enhanced superoxide release reflects biochemical or immunological mechanisms or possibly both.

This work was supported by grants from the Arthritis and Rheumatism Council. We are indebted to Ms B Bessac for skilful technical assistance.

\section{References}

1 Banford J C, Brown D H, Hazelton R A, McNeil C J, Sturrock R D, Smith W E. Serum copper and erythrocyte superoxide dismutase in rheumatoid arthritis. Ann Rheum Dis 1982; 41: 458-62.
2 Lunec J, Halloran S P, White A G, Dormandy T L. Free radical oxidation (peroxidation) products in serum and synovial fluid in rheumatoid arthritis. J Rheumatol 1981; 8: 233-45.

3 Hall N, Blake D R, Bacon P A. Serum sulphydryl levels in early synovitis. J Rheumatol 1982; 9: 593-6.

$4 \mathrm{McCord} \mathrm{J} \mathrm{M}$. Free radicals and inflammation; protection of synovial fluid by superoxide dismutase. Science 1974; 185: 529-31.

5 Greenwald R, Moy W W. Inhibition of collagen gelation by action of the superoxide radical. Arthritis Rheum 1979; 22: ڤ) 251-9.

6 Goldstein I M, Roos D, Kaplan H B, Weismann G. Comple- $\vec{\circ}$ ment and immunoglobulins stimulate superoxide production by $\vec{\overrightarrow{ }}$ human leucocytes independently of phagocytosis. J Clin Invest $\vec{\omega}$ 1976; 56: 1155-63.

7 Babior B M. Oxygen dependent microbial killing by phagocytes (parts 1 and 2). $N$ Engl J Med 1978; 298: 659-68, 721-5.

8 Repine J E, White J G, Clawson C C, Holmes B M. The $\vec{c}$ influence of phorbol myristate acetate on oxygen consumption by polymorphonuclear leucocytes. J Lab Clin Med 1974; 83: 911-20.

9 Kitagawa S, Takaku F, Sakamoto S. A comparison of the superoxide releasing response in human polymorphonuclear leucocytes and monocytes. J Immunol 1980; 125: 359-64. C

10 Curnutte J T, Babior B M, Karnovsky M L. Fluoride mediated activation of the respiratory burst in human neutrophils. J Clin $\frac{c}{d v}$ Invest 1979; 63: 637-47.

11 Van Furth $R$. The origin of phagocytic cells in the joint and bone. Scand J Rheumatol 1981; suppl 40: 13-20.

12 Cleland L G, Betts W H, Vernon-Roberts B, Bielicki J. Role of iron and influence of antiinflammatory drugs on oxygen derived free radical production and reactivity. $J$ Rheumatol 1982; 9:O 885-92.

13 Davis P, Johnston C, Miller C L, Wong K. Effects of gold compounds on the function of phagocytic cells. Arthritis Rheum 1983; 26: 82-6.

14 Simchowitz L, Mehta J, Spilberg I. Chemotactic factor induced generation of superoxide radicals by human neutrophils. Arthri- $\overrightarrow{\overrightarrow{0}}$ tis Rheum 1979; 22: 755-63.

15 Oyanagui $Y$. Inhibition of superoxide anion production in non-stimulated guinea pig peritoneal exudate cells by antiinflammatory drugs. Biochem Pharmacol 1978; 27: 777-82.

16 Hurst N P, Bessac B, Nuki G. Monocyte superoxide aniond production in rheumatoid arthritis: preliminary evidence for $\bar{\varrho}$ enhanced rates of superoxide anion production by monocytes $\bar{\sigma}$ from patients receiving penicillamine, sodium aurothiomalate and corticosteroids. Ann Rheum Dis 1984; 43: 28-33.

17 Boyum A. Isolation of mononuclear cells and granulocytes $\subseteq$ from human blood. Scand J Clin lab Invest 1968; 21 (suppl 97): 77-89.

18 Loos H, Blok-Schut B, Kipp B, van Doors R, Meerhof L. Size distribution, electronic recognition and counting of human blood monocytes. Blood 1976; 48: 743-53.

19 Yam L T, Li C Y, Crosby W H. Cytochemical identification of monocytes and granulocytes. Am J Clin Pathol 1971; 55:O 283-90.

20 Weening R S, Wever R, Roos D. Quantitative aspects of the production of superoxide radicals by phagocytosing humare granulocytes. J Lab Clin Med 1975; 85: 245-52.

21 Van Gelder B F, Slater E C. The extinction coefficient of cytochrome c. Biochim Biophys Acta 1962; 58: 593-5.

22 Ropes M W, Bennet G A, Cobb S, Jacox R, Jessar R A. 1958 revision of diagnostic criteria for rheumatoid arthritis. Arthritis Rheum 1959; 2: 16-20.

23 Haataja M. Evaluation of the activity of rheumatoid arthritis Scand J Rheumatol 1975; 4 (suppl 7): 19.

24 Herlin T, Borregaard N, Kragballe K. On the mechanisms of enhanced monocyte and neutrophil cytotoxicity in severe psoriasis. J Invest Dermatol 1982; 79: 104-8. 
25 Waytz P H, Douglas S D. Increased antibody dependent cell mediated cytotoxicity by monocytes from patients with rheumatoid arthritis. Arthritis Rheum 1979; 22: 490-4.

26 Carter S D, Bourne J T, Elson C J, Hutton C W, Czudek R, Dieppe P A. Mononuclear phagocytes in rheumatoid arthritis: Fc-receptor expression by peripheral blood monocytes. Ann Rheum Dis 1984; 43: 424-9.

27 Ezecowitz R A B, Bampton M, Gordon S. Macrophage activation selectively enhances expression of $\mathrm{Fc}$ receptors for IgG2a. J Exp Med 1983; 157: 807-12.

28 Walker N S. Mediation of macrophage cytolytic and phagocytic activities by antibodies of different classes and class specific Fc receptors. J Immunol 1977; 119: 367-73.

29 Cohn $\mathrm{Z}$. The activation of mononuclear phagocytes: fact, fancy and future. J Immunol 1978; 121: 813-6.

30 Pick E, Mizel D. Role of transmethylation in the elicitation of an oxidative burst in macrophages. Cell Immunol 1982; 72: 277-85,

31 Min-Fu Tsan, Chen J W. Oxidation of methionine by human polymorphonuclear leucocytes. J Clin Invest 1980; 65: 1041-51.

32 Bonvini E, Bougnoux P, Stevenson H C, Miller P, Hoffman T. Activation of the respiratory burst in human monocytes is associated with inhibition of methionine-dependent methylation of neutral lipids and phospholipids. J Clin Invest 1984; 73: 1629-37.

33 Hirata F, Axelrod J. Phospholipid methylation and biological signal transmission. Science 1980; 209: 1082-90.

34 Pike M C, Snyderman R. Transmethylation reactions regulate affinity and functional activity of chemotactic factor receptors in macrophages. Cell 1982; 28: 107-14.

35 McKeown M J, Hall N D, Corvalan R F. Defective monocyte accessory function due to surface sulphydryl (SH) oxidation in rheumatoid arthritis. Clin Exp Immunol 1984; 57: 607-13.

36 Murray H W, Cohn Z A. Macrophage oxygen dependent antimicrobial activity III. Enhanced oxidative metabolism as an expression of macrophage activation. J Exp Med 1980; 152: 1596-609.

37 Walker L, Lowrie D B. Killing of mycobacterium microti by immunologically activated macrophages. Nature 1981; 293: 69-70.

38 Metzger Z, Hoffeld J T, Oppenheim J J. Macrophage mediated suppression. I Evidence for participation of both $\mathrm{H}_{2} \mathrm{O}_{2}$ and prostaglandins in suppression of murine lymphocyte proliferation. J Immunol 1980; 124: 983-8.

39 Novogrodsky A, Ravid A, Rubin A L, Stenzel K H. Hydroxyl radical scavengers inhibit lymphocyte mitogenesis. Proc Natl Acad Sci USA 1982; 79: 1171-4.

40 Goust J M. Sodium periodate induced human suppressor cells for polyclonal B-cell activation. Clin Lab Immunol 1982; 8: 197-202.

41 Panayi G S. Does rheumatoid arthritis have a clinicopathological spectrum similar to that of leprosy? Ann Rheum Dis 1982; 41: 102-3.

42 Dawkins R L, Zilko P J, Carrano J, Garlepp M J, McDonald B. Immunobiology of D-penicillamine. J Rheumatol 1981; 8 (suppl. 7): $56-61$. 